\title{
Geschäftsbericht 2019 der FMH Services Genossenschaft
}

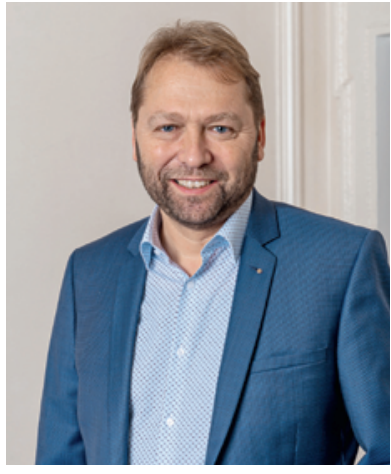

Dr. med., MLaw Beat Bumbacher Präsident der Verwaltung FMH Services Genossenschaft

Das Geschäftsergebnis 2019 der FMH Services Genossenschaft wurde durch die positive Entwicklung der Finanzanlagen entscheidend geprägt. Die Kapitalanlagen wiesen 2019 erfreuliche Erträge aus, welche die Substanz des Unternehmens weiter stärken. Die Bilanz der FMH Services Genossenschaft zeigt eine gesunde Struktur.

Die im operativen Bereich tätige FMH Consulting Services AG hat 2019 erfolgreich gearbeitet. Das Dienstleistungsangebot wurde durch eine neue Stellen- und Praxisplattform ausgebaut und modernisiert. Durch diverse Aktivitäten gelang es, die Kundenbeziehungen weiter zu vertiefen. Der Geschäftsbericht 2019 kann auf unserer Website www.fmhservices.ch eingesehen werden.

Als Präsident der Verwaltung des Unternehmens weiss ich, dass sowohl die Genossenschafterinnen und Genossenschafter als auch unsere Kundinnen und Kunden ganz wesentlich an dieser Entwicklung beteiligt sind. Ich möchte mich für diese Zusammenarbeit sehr bedanken. Der Erfolg der Vergangenheit ist uns Verpflichtung für weitere, richtungsweisende Schritte. Dabei verfolgen wir immer das Ziel, Ihnen jeden Tag Entlastung zu bieten, damit Sie sich als Ärztinnen und Ärzte auf Ihre eigentlichen Kernaufgaben konzentrieren können. Wie Sie auch, spüren wir bei FMH Services derzeit die Folgen der Krise um Covid-19; unsere Tätigkeit und auch das erwartete Geschäftsergebnis sind 2020 davon erheblich tangiert. Wie gewohnt werden wir Ihnen auch in diesen neuartigen und herausfordernden Situationen jederzeit beiseitestehen. Ich nutze gerne die Gelegenheit, allen Mitarbeiterinnen und Mitarbeitern der FMH Services für ihre erfolgreiche und engagierte Tätigkeit ganz herzlich zu danken. Darin eingeschlossen sind sämtliche Mitglieder unseres engmaschigen und schweizweiten Partnernetzwerks.

\section{Rapport de gestion 2019 de la coopérative FMH Services}

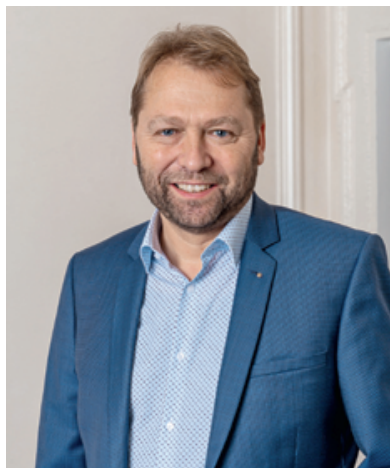

Dr méd. Beat Bumbacher MLaw, président du conseil d'administration de la coopérative FMH Services

Le résultat d'exploitation 2019 de la coopérative FMH Services a été fortement marqué par l'évolution positive des placements financiers. Les produits des placements réjouissants en 2019 renforcent la substance de l'entreprise. Le bilan de la coopérative FMH Services présente une structure saine.

FMH Consulting Services AG, active dans le domaine opérationnel, a très bien travaillé en 2019. L'offre de prestations a été élargie et modernisée avec une nouvelle plate-forme des emplois et des cabinets. Diverses activités ont permis d'approfondir les relations avec la clientèle. Le rapport de gestion 2019 peut être consulté sur notre site www.fmhservices.ch

En tant que président du conseil d'administration de l'entreprise, je sais que tant les sociétaires que les clientes et clients participent activement à ce développement. Je tiens à les remercier vivement pour leur collaboration. Le succès du passé nous motive pour franchir d'autres étapes décisives. Ce faisant, nous visons toujours l'objectif de vous décharger au quotidien pour que vous puissiez, en tant que médecins, vous concentrer sur vos tâches essentielles. Comme vous, nous ressentons actuellement l'impact de la crise du Covid-19 chez FMH Services. Notre activité et également le résultat d'exploitation attendu en 2020 seront directement impactés. Comme à l'accoutumée, nous serons à vos côtés, aussi dans cette situation inédite et difficile.

Je saisis l'opportunité pour adresser mes chaleureux remerciements à tous les collaborateurs et collaboratrices de FMH Services pour leur engagement et leur travail fructueux. Bien sûr, cela inclut tous les membres de notre dense réseau de partenaires en Suisse. 